
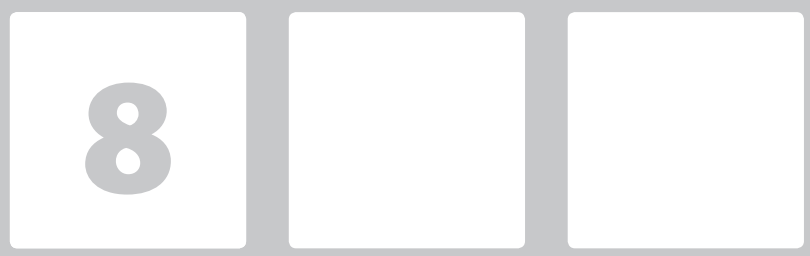

\title{
TENSÕES ORGANIZACIONAIS INERENTES COMO ELEMENTO DISTINTIVO À NATUREZA DOS NEGÓCIOS SOCIAIS
}

\section{Inherent organizational tensions as a distinctive element of the nature of social business}

\section{Seimor Walchhütter}

Doutor (2017) em Administração. Professor do curso de Graduação em Administração do Centro Universitário FEl. São Paulo, SP. Brasil. email:wseimor@fei.edu.br

\section{Edson Sadao lizuka}

Doutor (2008) em Administração Pública e Governo. Professor do curso de Graduação em Administração e do Programa de Mestrado e Doutorado em Administração do Centro Universitário FEl. São Paulo, SP. Brasil.email:esadao@fei.edu.br

\section{RESUMO}

Os Negócios Sociais (NS) são como organizações lucrativas e possuem, simultaneamente, um propósito social e, em alguns casos, ambiental. A necessidade de conciliar esses objetivos pode fazer com que os NS sofram tensões organizacionais específicas em suas atividades. Nesse sentido, a complexidade que apresenta esse campo, devido ao seu caráter aparentemente axiomático, é justamente o fator motivacional dessa pesquisa, que tem por objetivo compreender as tensões relativas aos NS. Por meio de uma revisão da literatura em NS e de achados empíricos a partir de um estudo de casos múltiplos, foi possível identificar que os NS enfrentam desafios únicos ao combinarem objetivos distintos. Os resultados desta pesquisa demonstram que as tensões que ocorrem nas quatro dimensões organizacionais identificadas nos estudos de Smith, Gonin e Besharov (2013) proporcionam um desequilíbrio permanente característico a esse tipo organizacional que o distingue de organizações provenientes de outros setores da sociedade, identificadas nesse artigo como: tensões relacionados ao desempenho, à aspectos organizacionais, ao pertencimento e à aprendizagem, as quais, de acordo com a revisão teórica e achados empíricos, são inerentes aos NS.

Palavras-chave: Negócios Sociais; Empreendedorismo Social; Tensões Organizacionais.

\section{ABSTRACT}

Social Business (SB) is seen as profitable organizations that has both a social purpose and, in some cases, an environmental purpose. The need to reconcile these goals can cause SB to experience specific organizational tensions in their activities. In this sense, the complexity of this field, due to its apparently axiomatic character, is precisely the motivational factor of this research that aims to understand the tensions related to SB. Through a literature review in NS and empirical findings from a multiple case study, it was possible to identify that NSs face unique challenges by combining different objectives. The results of this research demonstrate that the tensions that occur in the four organizational dimensions identified in the studies of Smith, Gonin and Besharov (2013) provide a permanent imbalance characteristic of this organizational type that distinguishes it from organizations from other sectors of society: performance-related tensions, organizational aspects, belonging and learning, which, according to the theoretical review and empirical findings, are inherent to NS.

Keywords: Social Business. Organizational Tensions. Social Entrepreneurship 


\section{INTRODUÇÃO}

Em vários países do mundo, sejam países desenvolvidos ou de sociedades em desenvolvimento, observa-se o surgimento de movimentos que procuram minimizar os problemas sociais e ambientais. Esses movimentos, intensificados pelas ações da sociedade civil, procuram aproximar a agenda entre empresas privadas e governamentais de forma colaborativa. A partir dessa proposta de colaboração intersetorial, nota-se frequentemente o surgimento de um tipo específico de organização, os Negócios Sociais (NS), que procuram equilibrar objetivos inicialmente compreendidos como antagônicos entre si: geração de valor social, minimização de passivos ambientais e sustentabilidade financeira.

Conforme os estudos de Battilana et al. (2014), os NS podem ser vistos como empreendimentos que resolvem problemas sociais por meio de mecanismos de mercado. Como consequência, nesse tipo de empreendimento há um compromisso social alcançado por meio de atividades comerciais pela oferta de bens e serviços. Nesta busca, os autores afirmam que muitos NS falham ao priorizar os clientes de suas atividades comerciais em detrimento dos beneficiários de suas atividades sociais, por dependerem financeiramente dos primeiros. Como consequência da necessidade de atingir objetivos concomitantes, os NS podem incorrer no risco de desviar-se de um ou de outro de seus objetivos, o que gera conflitos e tensões no exercício de suas atividades - parte desses conflitos ocorre pela necessidade de maximizar retorno social com retorno econômico-financeiro.

Nesse contexto, o objetivo desse artigo é compreender as tensões que ocorrem nos NS nas quatro dimensões (desempenho, aspectos organizacionais, aprendizagem e pertencimento) apresentadas por Smith, Gonin e Besharov (2013). Uma análise de quatro casos de NS - o agente financeiro Avante, a empresa de manufatura Goóc, o banco Pérola de microcrédito e o Moradigna, empresa da construção civil - é utilizada para atender a essa proposta de pesquisa e avançar na resposta da seguinte questão: em que medida as tensões constituem-se como elemento teórico para a compreensão dos Negócios Sociais?

Defende-se a proposta desse artigo por três razões: a primeira a partir do crescimento do tema, já destacado pela literatura em Doherty, Haugh e Lyon, (2014); por diferentes autores apontarem à necessidade de realização de estudos empíricos, conforme destacam Williams e Nadin (2011) e ROMANI-DIAS et al., 2016); e em terceiro, de acordo com os resultados encontrados nos estudos de Tracey, Phillips e Jarvis (2011) a discussão sobre a natureza dos NS ainda é vista por parte da literatura como sendo nova e heterogênea. Acredita-se, portanto, que o estudo das tensões enfrentados pelos NS pode auxiliar a caracterizá-los e distingui-los enquanto um tipo específico de organizações.

Esse artigo está estruturado em cinco seções, além dessa introdução. Inicialmente são abordados os principais conceitos relacionados às tensões em NS, com a finalidade de compor o referencial teórico do estudo. As seções seguintes tratam da metodologia adotada na pesquisa e da descrição dos quatro NS selecionados. Nas últimas duas seções são analisados os resultados encontrados no estudo, a partir dos quais são elaboradas as proposições, assim como são tecidas as considerações finais do trabalho, destacando-se suas limitações e sugestões de pesquisas futuras dentro do tema.

\section{TENSÕES EM NEGÓCIOS SOCIAIS}

Se, por um lado, há uma emergente quantidade de estudos sobre Negócios Sociais, tanto em âmbito nacional quanto em âmbito internacional, por outro, as literaturas sobre o tema ainda não encontram convergência entre si em relação aos conceitos que definem este fenômeno social. Por trazerem definições que em alguns aspectos são distintas, verifica-se que a discussão e a compreensão sobre NS são complexas e de difíceis interpretações, conforme já afirmaram autores como Borzaga, Depedri e Galera (2012). Esta complexidade também é observada porque os NS pretendem atender demandas sociais - incluindo-se demandas ambientais - e, concomitantemente, buscam obter equilíbrio financeiro (SMITH; LEWIS, 2011; BATTILANA; LEE, 2014).

Sobre as demandas ambientais, cabe observar que, de acordo com Moura, Comini e Teodósio (2015), embora as demandas sociais sejam mais 
profundamente previstas e tratadas em teorias sobre o tópico, as demandas ambientais também constituem um dos pilares deste tipo organizacional. No artigo ora apresentado, assim como nos trabalhos de Doherty, Haugh e Lyon (2014), a ênfase está nos aspectos sociais. No entanto, abordagens referentes à inclusão social a partir de aproveitamento de materiais reutilizáveis ou de desuso que reduzem passivos ambientais e ajudam na resiliência do planeta também são contemplados.

Como consequência de seus objetivos múltiplos, os gestores de NS deparam-se com paradoxos organizacionais, os quais são definidos por Jay (2013, p.140) como "demandas contraditórias e inter-relacionadas que existem simultaneamente, estão interligadas, e persistem ao longo do tempo". Os paradoxos podem ser encontrados na própria definição que autores proeminentes sobre o tema trazem, como Bornstein e Davis (2010, p.1), que definem os Negócios Sociais como consequência do Empreendedorismo Social, sendo "um processo pelo qual indivíduos constroem ou transformam organizações com o propósito de resolver problemas sociais". Yunus (2006, p.14), por sua vez, afirma que NS pode ser "qualquer iniciativa que procure ajudar pessoas". Enquanto isso, Mair e Martí (2006, p.37) e Zahra et al. (2009, p.519), respectivamente, procuram ser mais específicos ao se referirem aos Negócios Sociais como empreendimentos sociais: "processo inovativo que envolve recursos que buscam oportunidades de promover mudanças sociais ao serem orientados a essas demandas" ou "empreendimentos que exploram oportunidades com o intuito de promover bem estar ao criar novas maneiras de gerenciar negócios".

Nesse sentido, modelos teóricos que procuram dar um direcionamento à compreensão analítica dos impactos que podem proporcionar os Negócios Sociais, constituem-se como um desafio, devido a complexidade e natureza inerentes dos modelos individuais de cada organização. Margiono, Zolin e Chang (2018, p.4) afirmam que os modelos de negócios sociais estão em um espectro entre a criação de valor social e da maximização dos lucros. Os autores propõem entender os negócios sociais através de seus blocos de construção, começando com o propósito da organização ao identificar sua missão ou valor social, e então trazendo à lógica de mercado os resultados financeiros, os quais dependerão da particularidade do tipo de modelo de negócios (MARGIONO; ZOLIN; CHANG, 2017, p.10).

Em uma linha similar, Defourny e Nyssens (2017) distinguem os modelos entre interesse geral (do estado), interesse de capital (das corporações) e interesse mútuo (da sociedade), assumindo que os empreendimentos sociais encontram-se ao longo deste espectro. Essa sugestão de se construir um modelo analítico avança o debate e propões que o hibridismo de recursos resulta da mistura dos resultados mercantis e "não mercantis". Os autores ainda identificam quatro tipos diferentes de negócios sociais, quais sejam: negócios sociais (especificamente com interesses de capital presentes), empresas sem fins lucrativos, empresas do setor público e cooperativas - as três últimas direcionam os lucros à missão social.

Uma das principais correntes de definição de NS está na ênfase associada aos objetivos sociais. Peredo e MClean (2006) propõem que esses objetivos sejam um "continuum", ou seja, que os objetivos sociais estejam atrelados aos objetivos estratégicos da própria empresa. Em outras palavras, defendem que os objetivos sociais propostos causem, necessariamente, impacto social positivo e abrangente na sociedade, distinguindo, desse modo, esse tipo organizacional de empresas privadas tradicionais. Este pressuposto é convergente com os estudos de Zahra et al. (2009), para quem empresas tradicionais não estão orientadas à maximização de impactos sociais, e sim dos lucros.

Parte-se, portanto, do seguinte pressuposto: os gestores de NS, ao terem que optar por escolhas que podem ser excludentes (paradoxos organizacionais), enfrentam tensões em suas decisões. Desta forma, pesquisas sobre as tensões podem auxiliar na compreensão dos NS. Em seu estudo, Smith e Lewis (2011) questionam se as tensões são inerentes aos sistemas organizacionais ou formam-se a partir de uma realidade socialmente construída (BERGER; LUCKMANN, 2008). Na medida em que os NS buscam conciliar objetivos aparentemente opostos, como obter lucro e promover impacto social e ambiental positivos, pode ocorrer uma situação na qual a instabilidade se faz presente de maneira constante e que, portanto, tende a contribuir para que os indivíduos envolvidos na organização construam dinamicamente suas percepções e significados do que seja um NS. 
Os autores também apresentam quatro dimensões de tensões organizacionais, quais sejam: (i) de desempenho; (ii) de organização; (iii) de aprendizagem; (iv) de pertencimento (SMITH; LEWIS, 2011; SMITH; GONIN; BESHAROV, 2013).

As tensões de desempenho (i) caracterizam-se pela pluralidade das partes interessadas. Um exemplo disso é a competição por resultados opostos, como quando as métricas qualitativas para medir o desempenho social da organização são opostas às métricas quantitativas para medir o desempenho financeiro. A otimização do resultado de uma parte, neste caso, implica na redução dos resultados da outra. Tensões a partir da dimensão de desempenho exigem, de acordo com os autores, que os gestores optem por maximização dos resultados de uma das partes em detrimento dos resultados sobre os benefícios sociais da outra.

As demandas concorrenciais de processos e práticas organizacionais a partir da cultura do empreendimento ao longo dos anos, por sua vez, caracterizam as tensões de organização (ii) propostas pelos autores. Ou seja, são paradoxos causados pela competição, empoderamento e direção, a partir dos quais emergem as tensões referentes à organização. Nos NS essa situação torna-se mais evidente na escolha entre aumentar a produtividade por meio da contratação de indivíduos mais especializados no processo produtivo, ou optar por indivíduos com baixa capacitação, pleiteando o caráter de inclusão social de indivíduos provenientes de uma população com reduzida mobilidade social.

Os gestores, ao procurarem gerir as tensões relacionadas à organização podem criar um equilíbrio dinâmico e promover a aprendizagem e a criatividade. Esse tipo de tensão também pode ajudar os empreendimentos a serem mais flexíveis e resilientes, fomentando uma tomada de decisão mais dinâmica. No entanto, incluir pessoas com reduzida mobilidade social como, por exemplo, idosos e ex-presidiários, são escolhas aparentemente contrárias à busca por maior produtividade, o que gera um tipo de tensão organizacional. Trata-se, assim, de uma relação de custos e recompensas vivenciada pela organização.

As tensões de aprendizagem (iii), por sua vez, emergem em situações de mudança, as quais ocorrem com frequência nesse tipo de empreendimento. Os gestores e demais pessoas pertencentes aos NS pre- cisam aprender de maneira constante, pois trata-se de um empreendimento que convive com situações de ampliação das suas margens de lucro ao mesmo tempo em que ampliam seu impacto socioambiental - e para isso não existe fórmula simples, correta ou estática. Por fim, as tensões de pertencimento (iv) envolvem a ação coletiva em detrimento da subjugação do indivíduo para o benefício do todo. São aquelas que lidam com o interesse individual versus o interesse coletivo. Nesse sentido, os NS congregam profissionais diversos e que muitas vezes possuem perfil comumente encontrado em uma organização não governamental (ONG) sem fins lucrativos e outros com perfil similar ao do mercado privado tradicional. Dito de outra forma, quando um NS caminha para aumentar seu impacto social e ambiental, profissionais com perfil de mercado privado podem se desestimular por esse tipo de direcionamento estratégico e, nesse contexto, sentirem-se com "fraco pertencimento" - o inverso também pode acontecer.

Na seção a seguir discutiremos e também apresentaremos os procedimentos metodológicos para coleta, tratamento e análise dos dados primários e secundários em quatro diferentes organizações. Discutindo, nesse sentido, a importância das tensões inerentes aos negócios sociais em diferentes realidades.

\section{METODOLOGIA}

Esse artigo utilizou entrevistas e análise documental como principais fontes de coleta de dados. Foram estudados quatro NS com a finalidade de atingir o objetivo de pesquisa proposto. A pesquisa tomou como base as oito etapas propostas por Eisenhardt (1989) para o estudo dos empreendimentos, quais sejam: (i) Definição da questão de pesquisa (apresentada na seção de Introdução); (ii) seleção e justificativa dos empreendimentos a serem analisados; (iii) estabelecimento de métodos distintos de coleta de dados; (iv) aproximação com o campo; (v) análise dos dados coletados; (vi) elaboração de discussões e/ou proposições; (vii) cobertura da literatura; (viii) contribuição à discussão teórica.

Para responder às etapas propostas, os empreendimentos foram selecionados a partir de um critério intencional (ii). Este critério foi escolhido pelo fato 
de os empreendimentos pertencerem a diferentes segmentos de mercado e por adotarem modelos de negócios distintos, com o intuito de detectar possíveis convergências e divergências e possibilitar a compreensão desse fenômeno de forma abstrata e analítica, de forma a contribuir com um avanço teórico no campo organizacional.

Além disso, os empreendimentos investigados se auto intitulam como NS, e destacam que trabalham com a inclusão social de indivíduos em situação de vulnerabilidade social, tais como: idosos, ex-presidiários, grupos com baixa mobilidade no mercado de trabalho e públicos de baixa renda em geral. Justifica-se individualmente a escolha de cada um dos empreendimentos a partir das características singulares que cada um apresenta. Por exemplo, a Avante distingue-se pelo fato de ter como um de seus principais acionistas um especialista em públicos da base da pirâmide, conforme preconizam os estudos de Prahalad (2005). Na Goóc, há aspectos de crenças religiosas e culturais de seu fundador, que impactam em sua forma de ser e agir e relacionam-se às tensões de decisões, conforme estudo de Smith, Gonin e Besharov (2013). O Banco Pérola, por sua vez, foi um dos pioneiros na concessão de microcréditos para públicos de baixa renda no Brasil. Além disso, trata-se de um modelo de negócio que possui similaridades com um dos principais NS, o Grameen Bank, criado pelo vencedor do prêmio Nobel da Paz de 2006, Muhammad Yunus (YUNUS; MOINGEON; LEHMANN-ORTEGA, 2010). Por fim, o Moradigna foi empreendido com o propósito de melhorar a vida de pessoas da comunidade por meio de reformas rápidas. Seu modelo de negócios indica, conforme Yunus (2006), que os dividendos retornem ao negócio e não ao acionista ou proprietário, justamente para proporcionar abrangência ao impacto social.

Seguindo as etapas propostas por Eisenhardt (1989), os passos seguintes para a construção do estudo consistem na definição dos métodos de coleta de dados da pesquisa (iii e iv) e na aproximação com o campo. Esse artigo utilizou como fontes de coleta de dados entrevistas a partir de roteiro de entrevistas, documentos e observação não participante, fontes amplamente utilizadas para o tipo de questão de pesquisa proposto (YIN, 2001). As 26 entrevistas realizadas foram presenciais, tiveram duração de duas horas e trinta minutos e ocorreram nas sedes das respectivas organizações entre o primeiro semestre de 2014 e o segundo semestre de 2015, em duas diferentes etapas. Por tratar-se de um tema relacionado às tensões em NS, optou-se por entrevistar tomadores de decisões dos empreendimentos. Nesta etapa exploratória e em função dos contatos iniciais, a visão e a percepção dos fundadores e gestores dos NS se constitui como um importante ponto de partida para a compreensão desse fenômeno organizacional.

Além das entrevistas, a visita aos empreendimentos permitiu uma observação não participante sobre os tipos de bens e serviços ofertados com o intuito de confirmar se correspondem às descrições dos gestores e às fotografias disponíveis nos catálogos e nos sites dos empreendimentos. Durante as entrevistas, documentos adicionais foram disponibilizados, permitindo, dessa forma, a triangulação de dados no estudo (v), respeitando a etapa cinco, tal como foi proposta por Eisenhardt (1989). A partir das análises realizadas e tomando como base a literatura sobre tensões em NS, foram elaboradas proposições que poderão contribuir com a discussão teórica sobre essa temática (vi a viii).

Uma das etapas referentes à coleta de dados, conforme propõe Yin (2001), norteia a importância de se levantar quantos dados forem necessários, sob fontes de pesquisa variadas, a fim de melhor subsidiar o estudo. Foram realizadas pesquisa do tipo desk-research, em que foi possível encontrar dados das empresas, principalmente a partir de seus websites e de documentos internos, como catálogos, folders, planilhas, materiais de comunicação e estatutos sociais (quando disponíveis). Estas informações coletadas foram reunidas a outras fontes de coleta de dados, como entrevistas e observação não participante, para a realização da análise.

Vale ressaltar que a técnica de observação não participante, conforme Flick (2004), foi utilizada porque permite a interação com o meio ambiente, estabelecendo uma trajetória de comunicação visual e riqueza de informações, as quais contribuem com a composição da análise e com inferências a partir da captura da dinâmica daquele contexto. A partir do uso dessa técnica foi possível desencadear o nível de aproximação e relacionamento entre os gestores 
e a equipe, o envolvimento e o compromisso dos funcionários em relação às suas atividades.

Esse tipo de abordagem metodológica para compreensão dos negócios sociais baseada na complexidade do processo de tomada de decisão, torna-se uma essencial estrutura para identificar, compreender e analisar diferentes tipos de tensões e atividades organizacionais destinadas a resolver problemas relacionados à pobreza, ao meio ambiente e social dentro de realidades sociais distintas em contextos culturais e econômicos. Assim, na seção seguinte, apresentamos os casos selecionados, que nos ajudarão a entender as tensões em diferentes níveis organizacionais.

\section{OS CASOS SELECIONADOS}

Nessa seção serão descritas as principais características e justificativas para a escolha dos quatro empreendimentos selecionados para o estudo, quais sejam: Avante, Goóc, Banco Pérola e Moradigna.

\subsection{Estudo 1 - 0 agente financeiro Avante}

A Avante com VC Soluções e Participações SA, nome oficial da Avante, é um agente financeiro que localiza-se na região central de São Paulo e possui outro escritório dentro da comunidade de Paraisópolis, uma das três maiores Comunidades de São Paulo. A Avante iniciou suas operações, ainda como uma startup, em setembro de 2012, por iniciativa de um jovem empreendedor - Bernardo Bonjean, na faixa dos 35 anos de idade, ex-corredor da Paris Dacar, executivo atuante na bolsa de valores e detentor de uma visão de negócios abrangente e eficaz que contou com os conhecimentos adquiridos na cadeira de inovação da Harvard University, nos Estados Unidos.

A missão da Avante é "humanizar os serviços financeiros", e está alinhada com sua visão, que é "ser a empresa mais confiável na prestação de serviços financeiros”. Dentre seus valores, constam: (i) diálogo sem fronteiras, onde é incentivada a "melhor ideia", qualquer pessoa tem liberdade de expressar sua opinião; (ii) calçar o sapato do cliente, o que significa criar empatia com o cliente e buscar entender a situação do ponto de vista dele - neste caso, faz-se o seguinte questionamento: "se eu fosse meu cliente, eu faria isto que estou propondo?"; (iii) liderar pelo exemplo, não apontar erros e nem de criticar hábitos a ajuda mútua e o trabalho em equipe prevalecem; (iv) vencer e aprender com diversão, o que relaciona-se à crença de que as pessoas precisam ser felizes acima de tudo (AVANTE, 2016).

Desta forma, o modelo de negócios da Avante difere-se principalmente por não ser um banco em si, e sim um agente financeiro, conforme afirma um dos fundadores do empreendimento:

\begin{abstract}
Neste modelo de negócio a função primária da Avante é a oferta de microcréditos a beneficiários a partir do entendimento de suas necessidades e da viabilidade de proporcionar acesso aos produtos e serviços financeiros para pessoas sem possibilidade de garantia de pagamento, ou seja, de acesso aos créditos de outros agentes financeiros (AVANTE, 2016).
\end{abstract}

Os resultados econômicos e financeiros da Avante justificam suas operações: até 2015 o empreendimento operava em 116 cidades, 04 estados e detinha 116 agentes diretos responsáveis por 5 milhões de reais em empréstimos (microcréditos) para 2.842 beneficiários; até o final do quarto trimestre de 2016 a Avante pretende operar em mais de 300 cidades, 17 estados e deter em torno de 1.000 agentes de campo, alcançando o volume de 83 milhões de reais em microcréditos para 26.442 beneficiários, ampliando seu impacto social.

Destaca-se que uma das principais características sociais da Avante é a de entender que o empréstimo consignado "não necessariamente deve gerar um micro empreendimento, mas sim, melhorar a vida social do indivíduo, seja por reforma do imóvel, compra de eletrodomésticos ou televisores" (AVANTE, 2016), conclui seu fundador

\subsection{Estudo 2 - A Goóc Eco Sandals}

A Goóc, cujo nome significa raiz, em vietnamita, iniciou sua trajetória em 1979, quando seu fundador, o Sr. Thái Quang Nghiã, foi encontrado à deriva no Oceano Atlântico por um cargueiro da Petrobrás ao fugir de um campo de concentração de sua terra natal aos 19 anos de idade, por ser contra o regime totalitarista daquele país. Em 1987, Thái iniciou o grupo Domini, em Feira de Santana (Bahia) e em São 
Mateus (São Paulo), que, no ano de 2004, passou a se chamar Goóc.

Fundamentada na cultura e crenças religiosas de seu fundador, a missão da Goóc é "tornar o Brasil a referência do mundo em sandálias de pneu reciclado". Baseado nessa missão, a Goóc estabelece sua visão de "trabalhar com uma nova categoria de calçados: sandália de pneu reciclado, sandália de conteúdo, sandália de uma causa, sandália do futuro". Destacando as crenças que defende, Thaí afirma que "o produto é um meio e não um fim”, sendo que os valores do empreendimento estão em ter "alma oriental, mente ocidental e corpo brasileiro” (GOÓC, 2016).

Esse NS atua a partir da manufatura de sandálias, bolsas e mochilas por meio do uso de matérias-primas recicláveis provenientes de desuso ou inutilizadas para uso, como pneus velhos e lonas de caminhão descartadas. Por essa razão, adota etapas do conceito de logística reversa em sua produção.

Em 2003, a Goóc desenvolveu um acordo com seu principal parceiro de vendas e distribuição, a Avon do Brasil, responsável por aproximadamente $55 \%$ de seu faturamento, o qual gira em torno de 31 milhões de reais por ano, conforme dados de 2015. Além de seus resultados econômicos, o empreendimento apresenta como principais resultados sociais o emprego de mais de 960 colaboradores de baixa mobilidade social, entre os quais destacam-se ex-presidiários e idosos e, como resultados ambientais, a reciclagem de mais de 4 milhões de pneus no ano de 2007, tendo estabelecido a ousada meta de chegar a 30 milhões até o final de 2015 (GOÓC, 2016).

A Goóc apresenta superação aos desafios pautados em sua missão, conforme descreve um dos gestores entrevistados.

É um desafio muito grande, é um dilema, na verdade, não é um, são vários dilemas para você conseguir conciliar todos esses lados da moeda que envolvem o negócio. Então a gente sempre olha primeiro o que a gente não abre mão, seria do nosso tipo de material, o tipo de material, de onde ele vem para ser social também e para onde ele vai, e esse para onde ele vai [...] Então muitas vezes a gente já deixou de lançar produtos porque a gente não consegue vincular a proposta. Deixamos de estar em alguns clientes que até não concordam, e não deixam a gente expor os produtos [...]. Então a gente sempre faz algumas escolhas, há dilemas de decisão e entendemos que isso faz parte. Quanto à mão de obra é a mesma coisa, por isso a gente tem que ser muito mais criativo nos negócios (E2).
O que se percebe nesse trecho é uma preocupação do gestor em justificar como as tensões orientam a capacidade de gerir recursos da organização e servem como um meio para que procurem novas perspectivas de gestão (LÜSCHER; LEWIS, 2008). Os gestores, nesse sentido, dedicam esforços para reorganizar seu feixe de recursos, tanto interno quanto externo. A partir da realidade que encontram e por meio desse rearranjo, preparam-se para novos e constantes desafios oriundos das mudanças e competitividade de mercado.

\subsection{Estudo 3 - O Banco Pérola}

A Associação de Crédito ao Empreendedor Pérola, nome oficial do Banco Pérola, é uma Organização da Sociedade Civil de Interesse Público (Oscip). O banco Pérola foi fundado em 2008 e está localizado em Sorocaba, cidade do interior do estado de São Paulo. O banco foi idealizado por Alessandra França, paranaense formada em marketing que teve seu projeto selecionado entre os cinco melhores projetos do prêmio de empreendedorismo organizado pela Artemísia sobre negócio sociais, em 2009. O Banco Pérola tem como inspiração o banco Grameen, localizado na Índia e fundado por Muhammad Yunus, professor laureado com o prêmio Nobel da Paz no ano de 2006.

O Pérola tem a missão de "oferecer linhas de microcréditos orientados a indivíduos e empreendedores das classes $\mathrm{C}$, D e E, que proporcionem impacto social positivo". Como planos para o futuro o banco pretende "ser referência no setor de microcrédito orientado pelo impacto na melhoria de vida da população atendida do estado de São Paulo", conforme afirmado em sua visão, objetivo que pretende atingir por meio de valores como confiança, integridade, transparência, comprometimento, protagonismo, empreendedorismo, inovação e oportunidade (BANCO PÉROLA, 2016).

Conforme indica um dos gestores, o propósito do banco é social pelo fato de ser orientado e por não provocar maior endividamento ao tomador de crédito, ajudando, assim, em seu autodesenvolvimento. Destaca:

O Pérola é uma organização da sociedade civil de interesse público, uma OSCIP. O Pérola não é uma empresa privada, portanto, se a gente é uma organização da sociedade civil de 
interesse público, a nossa missão é de interesse público. Então, o que a gente faz? Uma concessão de crédito que é produtivo e orientado, é um crédito que é permitido para as organizações legalmente por terem enquadramento legal. Esse é o nosso propósito como uma Organizações da Sociedade Civil de Interesse Público (E2).

De acordo com o site do próprio empreendimento, o banco Pérola "atua com microcrédito produtivo orientado para a utilização do crédito. Isso significa que o processo de análise busca apoiar o empreendedor a ter uma clareza maior no tipo de investimento que ele vai realizar" (BANCO PÉROLA, 2016).

Como principais resultados, o banco já captou, até o ano de 2015, cerca de 1 milhão de reais pelo Fundo de Investimento Pérola e já realizou mais de 1000 operações financeiras. Além disso, já beneficiou mais de 600 empreendimentos e emprestou mais de 4 milhões de reais a diferentes empreendedores nas cidades de Sorocaba e Votorantim, regiões em que atua (BANCO PÉROLA, 2016).

\subsection{Estudo 4 - O Moradigna}

O Moradigna Construções e Assessoria Ltda, nome oficial do Moradigna, é uma empresa privada instalada na comunidade do Jardim Pantanal, na cidade de São Miguel Paulista, zona leste a 65km de São Paulo, em um escritório cedido pelo Instituto Alana, uma instituição não governamental (ONG).

A empresa foi fundada pelo Engenheiro Civil Matheus Cardoso, que hoje faz parte do quadro diretivo da empresa. Iniciou suas atividades em 2015, tendo como atividade principal aquelas relacionadas a Outras Obras de Acabamento e Construção. Detém faturamento atual de até 1 milhão de reais por ano e possui 9 funcionários entre agentes de obra e quadro administrativo.

A motivação para o desenvolvimento do projeto Moradigna se concentrava no desejo do jovem empreendedor em melhorar as condições de vida das pessoas a partir de reformas rápidas, chamadas pela empresa de "reformas express", as quais demandam entre três e cinco dias de duração. Sobre conciliar objetivos distintos, um dos gestores administrativos relata:
Não [desvia-se de seus objetivos sociais], porque ainda mais como o modelo do Moradigna que é um modelo que a gente financia o serviço, é muito clara a necessidade de tomada de capital para se oferecer o serviço. Portanto, tanto pra gente monetizar a empresa quanto monetizar, essa operação é muito importante pra atingir os objetivos sociais de mais pessoas impactadas (E1).

\section{E completa:}

Pois para nós, não são objetivos que divergem entre si, que se distanciam entre si, são objetivos muito atrelados no Moradigna. Não é, pelo menos no nosso modelo de negócios, os resultados sociais são apenas alcançados com os resultados financeiros, e os resultados financeiros são apenas alcançados com os resultados sociais, é uma venda de um serviço, né. Não tem como um não andar lado a lado com o outro (E2).

Já no decorrer de seu primeiro ano, o Moradigna realizou 60 reformas e pretende chegar nos próximos dois anos em 400 e atingir faturamento superior a 1 milhão de reais sob essa perspectiva de proporcionar qualidade de vida, conforto e segurança por meio da otimização dos processos de pequenas reformas para as classes de baixa renda. Destacando uma das principais características sociais do Moradigma, um de seus fundadores afirma que a visão que orienta a empresa é a de: "promover uma mudança significativa na qualidade de vida dos clientes por meio de moradias dignas" (MORADIGNA, 2015).

Embora o debate sobre os negócios sociais ainda seja considerado assistemático, as relações intersetoriais e os debates acadêmicos avançam na compreensão de um padrão comum aos negócios sociais: configuram-se como organizações orientadas a resolverem problemas sociais por meio de mecanismos de mercado. Em outras palavras, objetivos antes considerados paradoxais, por meio dos negócios sociais, agora são compreendidos por uma finalidade comum - criação de valor social ao mesmo tempo em que o equilíbrio financeiro passa a ser a prova da eficácia operacional, e não seu fim. A seção a seguir procura desenhar uma análise da existência inerente das tensões nessas organizações. 


\section{DISCUSSÃO}

Nessa seção serão analisados os quatro empreendimentos de acordo com as etapas definidas na metodologia. O primeiro caso é o do agente financeiro Avante, que pode ser conceituado como um empreendimento focado no público da base da pirâmide, e que foi iniciado a partir do fornecimento de microcrédito a um nicho de mercado potencial ainda inexplorado, como o da comunidade de Paraisópolis (SP). O destaque da Avante está em sua plataforma de oferta de produtos pela internet e na captação de seus clientes, trabalho realizado por seus agentes de campo, que baseiam a aprovação da concessão do crédito a partir da confiança e respeito com seus clientes. Este aspecto diferencia a Avante de outros empreendimentos de serviços bancários, o que pode ser evidenciado a partir da fala de um de seus gestores: "A empresa se esforça para que o aconselhamento seja feito em uma linguagem simples e acessível ao seu público. Algumas pessoas têm muito medo de ir ao banco, porque às vezes não entendem nada o que $o$ gerente fala".

Dessa forma, a Avante causa impacto social não apenas ao conceder microcrédito a quem não tem garantias de pagamento, mas também por procurar entender a necessidade do empréstimo e do auxílio em sua utilização de forma simples e humanitária, conforme afirmou o entrevistado. De acordo com o volume de microcréditos efetivos e pelo número potencial de novos clientes, a Avante mostra crescimento também em seu retorno sobre o investimento. Este crescimento é considerado pelo empreendimento como sendo substancial e pode ser ilustrado pelo interesse de organizações investidoras, como a Vox Capital, e de assessoria administrativa de especialistas nesse nicho de mercado.

É possível notar, nesse ponto, que uma discussão se inicia a partir do modelo de negócios proposto por Yunus (2006), no qual o lucro gerado deve ser reinvestido na própria atividade, tendo como exceção negócios criados por indivíduos pobres - Yunus é categórico ao afirmar que quando as pessoas são pobres, o objetivo maior deve ser o de tirá-las da pobreza, e não as constituir como fonte de riqueza. Este pensamento vai de encontro ao proposto por Prahalad e Hart (2002), que justificam os lucros como pressuposto para atrair investimentos em mercados em que a população é marginalizada. Neste caso, as capacidades dinâmicas das empresas devem ser orientadas para atingir escala e desenvolver tecnologias e processos operacionais e de gestão eficientes para propor produtos acessíveis a quem possui renda inferior a mil e quinhentos dólares anuais.

O ponto convergente nesses pressupostos está no propósito, mas diferem no modo de atingi-lo. $\mathrm{O}$ primeiro assume a otimização do lucro e o segundo visa a maximização desse. De acordo com Yunus, a otimização e não a maximização significa obter o equilíbrio entre esses dois objetivos - criação de valor econômico e criação de valor social. Prahalad também defende a transformação social a partir da criação de empregos gerados por novos empreendedores que vislumbrarão oportunidades rentáveis nesse nicho de mercado-alvo. Mas, ao se referir à população da Base da Pirâmide (BoP), ele define: "multinacionais complicaram os esforços dos pobres para construir sua subsistência, contudo o maior dano foi ignorá-los" (2005, p.51).

Nesse sentido, parece que o conceito se conecta mais em motivar o consumo e não em criar bem-estar a esse público-alvo. Este tipo de atividade central indica um desalinhamento em criar impacto social positivo, pois não visa desenvolver o indivíduo em sua plenitude para que ele mesmo crie capacitações e autodesenvolvimento para sair da linha da pobreza, e sim, endividá-lo, além de sua capacidade de pagamento, pelo desejo de compra que, supostamente, permitiria sua inclusão social. Nesse artigo parte-se do pressuposto que o modelo proposto por Yunus (2006) e corroborado por Sen e Mendes (2000), no qual o lucro otimizado deve garantir o direito à liberdade, está mais alinhado com a perspectiva da proposta dos Negócios Sociais. Negócios na BoP parecem não gerar tensões de desempenho, pois detém em sua base lógica aspectos como eficiência e eficácia, considerando esse público-alvo como uma opção estratégica, e não necessariamente como uma intencionalidade de proporcionar impacto social.

A compreensão sobre as tensões organizacionais inerentes aos Negócios Sociais nos leva a entender que a geração de oportunidades de negócios orientados para o público específico da BoP parece não necessariamente implicar uma mudança social. $\mathrm{O}$ 
fato de essa população ser considerada pobre não significa que não tenham condições de movimentar a economia, pelo contrário, podem ser vistos como um alvo de mercado valioso e potencialmente promissor em termos de lucratividade (PRAHALAD, 2005). A Goóc, por sua vez, gera impacto social a partir da contratação de mão de obra de baixa qualificação e de baixa mobilidade social, como ex-presidiários, idosos em geral e mulheres acima de 50 anos de idade. Este posicionamento está alinhado com as palavras de um de seus gestores, e evidencia a preocupação social da organização: "Antes de salvar o mundo, salve a si mesmo". A Goóc parece possibilitar essa "salvação" de si mesmo aos seus colaboradores.

Em relação à preocupação ambiental da empresa, as matérias-primas fundamentais para a manufatura das bolsas e calçados concentram-se em pneus e lonas de caminhão em desuso. Isso vai ao encontro dos valores do empreendimento, conforme defende o entrevistado: "faça consumo responsável, [...] pense em deixar um legado positivo às próximas gerações, daqui a 20, 30 e 50 anos". Para alcançar seus objetivos econômicos, o empreendimento tem como principal diferencial a escolha de pontos de venda diversificados, como os que estão presentes em estações do metrô da cidade de São Paulo.

Destaca-se ainda que a Goóc utiliza ferramentas que auxiliam em seu planejamento estratégico, como o Balance Score Card (BSC), com a finalidade de orientar seu processo produtivo e administrativo. Além disso, o empreendimento procura estabelecer acordos comerciais com parceiros de distribuição, como a Avon, empresa americana do segmento de cosméticos, que mantém uma unidade de negócios que promove em seu site a linha "Chinelos Goóc Durabem".

Um dos aspectos que podem ser destacados são os elevados custos que o empreendimento administra em relação à aquisição das matérias-primas e ao processo produtivo, gerando um tipo de tensão em sua atividade. $\mathrm{O}$ transporte, assim como a tecnologia para manufaturar produtos recicláveis, requer custos maiores que os necessários para operar com produtos tradicionais, o que impacta no preço de seu produto final, principalmente em relação à sua competitividade nos pontos de venda. Apesar dessas tensões, a frequência com que ocorrem as contratações de mão de obra não especializada e em vulnerabilidade social e o uso de matérias-primas recicláveis parecem demonstrar que a organização possui clareza em seu posicionamento na tomada de decisão, o que também é devido às crenças e valores de seu fundador.

O banco Pérola atua no setor de serviços por meio da oferta de microcrédito para população de baixa renda. Por meio desses empréstimos e do aumento de acesso a recursos financeiros das populações atingidas, o banco gera impacto social positivo. Um de seus gestores diz: "Entendo que o banco Pérola não é uma ONG, e sim um negócio social, que se diferencia de uma empresa tradicional por ser sustentável financeiramente ao exercer suas atividades por meio da geração de impacto social". Um aspecto relevante do banco Pérola é que ele iniciou sua trajetória oferecendo aos jovens educação tecnológica e cursos profissionalizantes; todavia, ao perceber que muitos jovens não tinham acesso a recursos financeiros em bancos tradicionais, mudou sua estratégia e passou a oferecer microcrédito orientado às atividades microempreendedoras desse público, evidenciando, desse modo, uma tensão sofrida pelo banco, ao ter que optar por uma mudança em sua atividade devido a um contexto de mercado.

Verifica-se que a concessão de microcrédito ofertado pelo banco Pérola detém baixo retorno financeiro e baixo volume de negócios, o que pode trazer dificuldades para o equilíbrio financeiro do empreendimento. Diante dessas dificuldades, o banco Pérola realizou parceria com o Fundo de Investimentos em Direitos Creditórios (FIDIC), a qual é fundamental para a sua continuidade, conforme afirma um dos entrevistados: "Sem o FIDC não sei se conseguiríamos manter o negócio", evidenciando tensões nas atividades do banco. Por ter que aumentar o volume de empréstimos a fim de subsidiar suas operações, ou aumentar a lucratividade de seus empréstimos, diminuindo assim, seus beneficiários, entende-se que esse empreendimento sofre tensões de decisão.

Por fim, o Moradigna, onde a discussão sobre o conceito de Negócios Sociais, conforme indica a literatura, possui interpretações diferentes. Nesse contexto, essa pesquisa questionou os entrevistados para entender o tema a partir de suas visões. Os resultados apresentaram convergência em relação ao propósito, ou seja, de que os Negócios Sociais não têm 
como pressuposto a maximização do lucro, e sim sua otimização. Com isso, a proposta de contribuir com o mundo social e ambientalmente não pode ser entendida como redução proporcional do lucro, sintetiza um dos entrevistados: "Sucesso para nós empreendedores sociais significa o quanto a gente alcança de um sonho grande que, no caso do Moradigna, são os 40 milhões de brasileiros a serem atendidos" (C3E1). A empresa estabelece uma relação viável entre o social e o econômico partir do modelo Yunus de negócio adotado, onde os dividendos não são distribuídos entre os acionistas, e sim reinvestidos no negócio para aumentar sua abrangência (YUNUS, 2006).

Dos achados de campo, constatou-se que todos os empreendimentos possuem um propósito de transformação social, mas que divergem entre si em relação aos meios adotados. Em relação ao impacto social da Goóc, como já dito, o objetivo é a transformação da vida dos indivíduos por meio de contratação formal e de treinamento que permitem a inserção social desses, por meio de seu desenvolvimento pessoal, empregabilidade e capacitação. Diferentemente ocorre nos contextos do agente financeiro Avante e do banco Pérola, em que o desenvolvimento e inclusão social de indivíduos ocorrem pelo empoderamento financeiro desse público de baixa renda, o que permite a criação de microempreendimentos. Esses microempreendimentos auxiliam no desenvolvimento da sociedade em que estão inseridos.

Em relação ao impacto ambiental, a Goóc utiliza matérias-primas recicláveis, como aproveitamento de jornais, pneus e lonas, reduzindo, dessa forma, o passivo ambiental de sua atividade. Essa característica não é tão evidente nos contextos dos empreendimentos Avante e banco Pérola, ambos atuantes no mercado financeiro.

Observou-se que alguns pressupostos que motivavam as decisões dos gestores são divergentes. $\mathrm{Na}$ Avante, partem de uma decisão mais racional, pois os objetivos estão associados a um nicho de mercado específico, que é o potencial de consumo de população considerada como base da pirâmide (PRAHALAD, 2005), característica que não foi encontrada nos demais empreendimentos. Esses pressupostos auxiliam na compreensão quanto a ausência ou presença de tensões nas decisões desses gestores em relação a algumas das dimensões dos estudos de Smith, Gonin e Besharov (2013).

Um ponto de destaque nos empreendimentos está nos valores que envolvem os gestores. Em todos foram encontradas tensões, mas nem sempre dessas tensões se originaram dilemas. A partir da observação não participante realizada na Goóc e no banco Pérola, foi possível identificar que os gestores dessas organizações detêm profundo sentimento sobre o propósito do empreendimento; a conquista dos benefícios sociais torna-se um sentimento de auto realização, enquanto a meta financeira significa uma etapa para a conquista da primeira.

Entre estes empreendimentos, a Goóc distingue-se pela prioridade social que demonstra em sua atividade, decorrente dos valores de seu fundador. Essa prioridade pode ser percebida pelas perdas financeiras que o empreendimento sofre ao empregar mão de obra que não atende aos requisitos de maximização da produção e por adotar matérias primas mais onerosas que as tradicionais, como os pneus e as lonas reciclados. O contexto da Avante, por sua vez, parece demonstrar que o empreendimento possui objetivos prioritariamente econômicos, apesar da importância social de sua atividade. Tomando como base a teoria sobre a temática e análise dos quatro empreendimentos selecionados para esse estudo, tornou-se possível sintetizar os tipos de tensões existentes em cada empreendimento que foram discutidos nessa análise, conforme Quadro 1:

Os estudos teóricos de Smith e Lewis (2011), que categorizam as tensões nos Negócios Sociais em quatro dimensões (performance financeira, aspectos organizacionais, senso de pertencimento e de aprendizagem), contribuíram ao entendimento das organizações estudadas a partir das mesmas categorias. As investigações de campo por meio do processo metodológico adotado permitiu compreender em quais níveis organizacionais prevalecem as tensões em cada uma dessas organizações. Desta forma, identifica-se que, independentemente do nível em que prevaleçam as tensões, todas as organizações as experimentam, fato que confirma a proposta dessa pesquisa ao propor que o tipo das tensões são específicos, inerentes e indissociáveis aos Negócios Sociais e, sendo assim, consideradas um elemento distintivo desse tipo organizacional. 
Quadro 1 Tensões Percebidas nos Negócios Estudados

\begin{tabular}{|c|c|}
\hline Tipo de tensão & Tensões percebidas nos Negócios Sociais \\
\hline \multirow[t]{3}{*}{ Organização } & $\begin{array}{l}\text { Mão-de-obra diversificada, sem treinamento ou de baixa mobilidade social que pode comprometer o cronograma de } \\
\text { entrega ou a produtividade do empreendimento (Goóc e Moradigna). }\end{array}$ \\
\hline & Custo operacional com a aquisição da matéria-prima reciclável com seus associados indiretos (Goóc). \\
\hline & Decisão sobre aumentar o volume ou os valores dos serviços oferecidos para sua sobrevivência (Banco Pérola). \\
\hline Pertencimento & $\begin{array}{l}\text { Cultura organizacional disseminada pelo fundador do empreendimento baseado em crenças e valores pessoais (de } \\
\text { inclusão social e ambientais) (Goóc e Moradigna). }\end{array}$ \\
\hline \multirow[t]{3}{*}{ Aprendizado } & $\begin{array}{l}\text { Combinar o retorno financeiro com as causas sociais e ambientais do propósito do empreendimento } \\
\text { (Goóc, Avante e Moradigna). }\end{array}$ \\
\hline & Necessidade de aprendizado constante e adaptação ao tipo de público-alvo escolhido (Banco Pérola e Avante). \\
\hline & $\begin{array}{l}\text { Notou-se que um dos processos de aprendizagem se faz por meio de troca de experiências com outras empresas com a } \\
\text { mesma orientação, como o projeto Vivenda (Moradigna). }\end{array}$ \\
\hline \multirow[t]{4}{*}{ Desempenho } & $\begin{array}{l}\text { Aumento do volume de serviços a fim de subsidiar as operações ou aumento dos valores dos serviços para alavancar a } \\
\text { lucratividade (Banco Pérola). }\end{array}$ \\
\hline & $\begin{array}{l}\text { As evidências que identificaram que houve resolução do conflito a partir de consenso da equipe no cumprimento de sua } \\
\text { missão. Tarefa que foi intermediada por sessões coachings profissionais e orientados aos gestores de forma individual e } \\
\text { coletiva (Moradigna). }\end{array}$ \\
\hline & Priorização das necessidades do cliente em detrimento de outros Stakeholders (Avante). \\
\hline & Disseminação do conceito do propósito social em toda a cadeia de produção (Goóc). \\
\hline
\end{tabular}

Fonte: Autores. Adaptado de Smith e Lewis, 2011, p.383

A partir do quadro, nota-se que as quatro dimensões de tensões estão presentes nos empreendimentos, entre as quais destacam-se as de aprendizado, identificadas nas quatro organizações. Outro ponto de destaque é a tensão sobre o desempenho do empreendimento identificada na Goóc; como exemplo dessa tensão está a disseminação do conceito do propósito social em toda a cadeia de produção.

Ademais, os Negócios Sociais enfrentam tensões sociais como, por exemplo, questões relacionadas às intenções de inclusão social, ao comprometimento dos colaboradores de acordo com seus objetivos pessoais e de carreira frente aos objetivos e metas da própria organização e, por fim, ao crescimento da organização e à geração e distribuição de renda frente às responsabilidades socioambientais.

Portanto, é possível identificar outros dois fatores analíticos relacionados aos NS: as tensões inerentes orientam a dilemas de decisão específicos, e assim, formam um ciclo dinâmico que se retroalimenta, formando um processo contínuo de significado e aprendizagem (IIZUKA; VARELA; LARROUDÉ, 2015).
Como forma de contribuir com a discussão teórica sobre as tensões existentes em NS, e a partir das entrevistas, análises dos documentos e observações realizadas nos NS, foram elaboradas duas proposições que visam auxiliar na compreensão do fenômeno estudado, conforme segue:

\section{Proposição 1: Todo Negócio Social sofre tensões inerentes a suas atividades.}

A tentativa de conciliar demandas sociais e econômicas nas organizações leva ao cenário de conflitos internos, gerando tensões nos NS. Estas tensões acontecem porque este tipo de empreendimento enfrenta conflitos de metas ou diferentes demandas entre seus diferentes stakeholders. Além disso, as discordâncias entre prioridades, foco em múltiplas metas, ganhos tangíveis como lucro financeiro versus ganhos intangíveis como motivação dos colaboradores também são fatores que propiciam o surgimento de tensões neste tipo de empreendimento. De fato, parece haver tensões nesse tipo organizacional, mesmo que em diferentes graus e níveis de intensidade. Foi isso que a pesquisa de campo indicou. Ou seja, o modelo 
teórico utilizado nesta pesquisa parece ser adequado para a compreensão dos NS, em diferentes ramos de atuação e formatos organizacionais.

\section{Proposição 2: As tensões existentes nos NS podem transformar-se em dilemas em seus processos decisórios.}

Os dilemas surgem a partir das tensões geradas pelos desafios que os NS enfrentam para atingirem suas metas econômicas, sociais e ambientais. Estes dilemas são gerados por existirem demandas competitivas e pela necessidade de gestores terem que tomar decisões conflitantes, que vão desde a forma de produção, contratação de mão de obra, definição do público-alvo, tipo de matéria-prima utilizada, entre outras. A Avante e a Goóc não demonstraram dilemas claros em seus processos decisórios. Isso pode ser explicado porque a primeira tem como foco a base da pirâmide, ou seja, trata-se de um empreendimento como outro qualquer, com a ressalva de possuir o público-alvo da baixa renda. A Goóc, por sua vez, parece ser influenciada pela crença religiosa de seu fundador e sua convicção de que o empreendimento deve ir num sentido contrário ao mercado tradicional, como contratar pessoas idosas e ex-presidiários, por exemplo.

\section{CONCLUSÃO}

Levando-se em conta o crescimento do interesse acadêmico sobre os NS, pesquisas que tragam exemplos empíricos de diferentes NS e de suas formas de atuação [ver (DOHERTY; HAUGH; LYON, 2014) para uma extensa revisão da literatura e agenda de pesquisa], não fornecem uma visão inédita sobre a natureza dos Negócios Sociais a partir de um elemento distintivo que os caracterizam, as tensões inerentes. Portanto, a lacuna teórica identificada nesta pesquisa se desenvolveu em compreender a natureza dos Negócios Sociais ao propor que as tensões nos NS são inerentes e se constituem como um elemento distintivo que os caracterizam (SMITH; LEWIS, 2011; SMITH; GONIN; BESHAROV, 2013).

Equilibrar o aspecto financeiro e o impacto socioambiental não é algo trivial e pode gerar um "desequilíbrio permanente" aos Negócios Sociais. Essa condição não é passível de ser considerada certa ou errada, mas consiste apenas em uma característica inerente aos Negócios Sociais. Muito embora se tenham tensões em outras organizações - públicas, privadas e da sociedade civil, as tensões relacionadas aos Negócios Sociais são inerentes, ou seja, as tensões nos Negócios Sociais distinguem-se essencialmente das tensões dessas outras organizações, pelo fato de não poderem ser resolvidas. As tensões inerentes estão além de obter uma solução: tentar "resolvê-las" implicaria simplesmente descaracterizar os Negócios Sociais. Isto é, se, por um lado, fosse eliminado o objetivo social como um dos focos da organização, ela se transformaria em uma empresa privada tradicional; de outra maneira, se fosse eliminada a necessidade de rentabilidade e lucratividade, a organização deixaria de ser uma empresa e se transformaria em uma organização sem fins lucrativos.

A lógica organizacional de um Negócio Social indica que os NS buscam otimizar os resultados financeiros motivados por razões éticas e não materiais. $\mathrm{O}$ crescimento da organização é um meio para atingir o resultado social a partir de sua missão (DOHERTY; HAUGH; LYON, 2014). Portanto, as tensões inerentes caracterizam os NS como organizações que estão em desequilíbrio constante por assumirem em sua natureza, objetivos distintos e excludentes entre si. Assim, as tensões existentes nos Negócios Sociais não são apenas necessárias, mas também fazem parte integrante dessas organizações como um fator principal de sua existência. Assim, eliminar as tensões destruiria a própria fundamentação da organização. Para este estudo foram analisados quatro NS de destaque em seus setores de atuação, tomando como base as etapas defendidas por Eisenhardt (1989). Os resultados de campo indicam que as quatro organizações investigadas, mesmo inseridas em mercados diferentes, possuem os mesmos pressupostos de tensão - ora em dimensões semelhantes, ora em dimensões distintas. Ou seja, possuem tensões específicas ao enfrentarem o desafio de equilibrar objetivos sociais e ambientais a partir de lógicas de mercado.

Esse artigo possui algumas limitações. A primeira delas refere-se ao fato de os quatro empreendimentos escolhidos serem originários da região Sudeste do país. O presente estudo não teve o propósito de, indutivamente, tratar da categorização de dilemas 
adicionais ao modelo proposto por Smith, Gonin e Besharov (2013). Além disso, estudos relacionados a NS em outros países não foram contemplados comparativamente. Levando em consideração as limitações de pesquisa e os resultados desse artigo, são propostas pesquisas futuras que tratem da Aprendizagem Organizacional em NS e da forma como eles podem identificar e lidar com tensões inerentes e possíveis dilemas. Também são propostos estudos que tragam maior abrangência regional, por exemplo, por meio da comparação entre regiões do Brasil ou de outros países (internacionalização dos NS). A pesquisa também abre espaço para análises complementares sobre fatores que possam influenciar a presença (ou não) de tensões inerentes, tais como a influência religiosa dos empreendedores, crenças e convicções de vida na gestão e tempo de vida da empresa.

\section{REFERÊNCIAS}

AVANTE. Propósito e Valores. Disponível em: $<$ https://www.avante.com.vc/quem-somos/\#valores>. Acesso em: 13 jul. 2016.

BATTILANA, J.; LEE, M. Advancing research on hybrid organizing-insights from the study of social enterprises. The Academy of Management Annals, [s.l.], v. 8, n. 1, p. 397-441, 11 fev. 2014. Disponível em: <https://doi.org/10.1080/19416520.2014.89361 5>. Acesso em: 19 abr. 2016.

BANCO PÉROLA. Nossa história e nossos resultados. 2016. Disponível em: <http://www.bancoperola. org.br>. Acesso em: 04 fev. 2016.

BERGER, P.; LUCKMANN, T. A construção social da realidade: tratado de sociologia do conhecimento. 28. ed. Petrópolis: Vozes, 2008.

BORNSTEIN, D.; DAVIS, S. Social entrepreneurship: what everyone needs to know. New York: Oxford University Press, 2010.
BORZAGA, C.; DEPEDRI, S.; GALERA, G. Interpreting social enterprises. Revista de Administração, São Paulo, v. 47, n. 3, p. 398-409, jul./sep. 2012.

DEFOURNY, J. \& NYSSENS, M. Fundamentals for an International Typology of Social Enterprise Models. Voluntas, vol. 28, n.1, p. 2469-2497, 2017a.

DOHERTY, B.; HAUGH, H.; LYON, F. Social enterprises as hybrid organizations: A review and research agenda. International Journal of Management Reviews, UK, v. 16, n. 4, p. 417-436, 3 jan. 2014. Disponível em: <https://doi.org/10.1111/ijmr.12028>. Acesso em: 10 mai. 2014

EISENHARDT, K. Building theories from case study research. Academy of Management Review, Nova York, v. 14, n. 4, p. 532-550, oct. 1989.

FLICK, U. Uma introdução à pesquisa qualitativa. 2. ed. Porto Alegre: Bookmam, 2004.

GOÓC. Missão. Disponível em: <http://goocecosandal.com.br $>$. Acesso em: 13 jul. 2016.

IIZUKA, E.; VARELA, C.; LARROUDÉ, E. Social business dilemmas in Brazil: Rede Asta case. Revista de Administração de Empresas, São Paulo, v. 55, n. 4, p. 385-396, jul./ago. 2015.

JAY, J. Navigating paradox as a mechanism of change and innovation in hybrid organizations. Academy of Management Journal, Nova York, v. 56, n. 1, p. 137-159, feb. 2013.

LÜSCHER, L. S.; LEWIS, M. W. Organizational change and managerial sensemaking: Working through paradox. Academy of Management Journal, Nova York, v. 51, n. 2, p. 221-240, 1 apr. 2008.

MAIR, J.; MARTÍ, I. Social entrepreneurship research: a source of explanation, prediction and delight. Journal of World Business, [s.l.], v. 44, n. 1, p. 3644, feb. 2006. 
MARGIONO, A., ZOLIN, R., \& CHANG, A. A typology of social venture business model configurations. International Journal of Entrepreneurial Behavior \& Research, v.24, n.3, P.626-650, 2018.

MORADIGNA. Fazer o bem. 2016. Disponível em: $<$ http://www.moradigna.com.br $>$.Acesso em: 04 fev. 2016.

MOURA, A.; COMINI, G.; TEODÓSIO, A. The international growth of a social business: a case study. Revista de Administração de Empresas, São Paulo, v. 55, n. 4, p. 444-460, jul./ago. 2015.

PEREDO, A.; MCLEAN, M. Social entrepreneurship: a critical review of the concept. Journal of World Business, [s.1.], v. 41, n. 1, p. 56-65, feb. 2006.

PRAHALAD, C.; HART, S. The fortune at the bottom of the pyramid. Strategy Business, [s.l.], n. 26, p. 1-26, 10 jan. 2002.

PRAHALAD, C. A riqueza na base da pirâmide: como erradicar a pobreza com o lucro. Porto Alegre: Bookman, 2005.

ROMANI-DIAS, M. et al. A pesquisa acadêmica sobre negócios sociais no Brasil e no mundo. In: ENCONTRO DA ANPAD, 40., 2016, Costa do Sauípe. Anais eletrônicos... São Paulo: ANPAD, 2016. p. 1-21. Disponível em: <https://www. researchgate.net/publication/319451286_A_ Pesquisa_Academica_sobre_Negocios_Sociais_ no_Brasil_e_no_Mundo>. Acesso em: $03 \mathrm{dez}$. 2016.

SEN, A.; MENDES, R. D. Desenvolvimento como liberdade. São Paulo: Companhia das Letras, 2000.

SMITH, W.; GONIN, M; BESHAROV, M. Managing social-business tensions: a review and research agenda for social enterprise. Business Ethics Quarterly, Cambridge, v. 23, n. 03, p. 407-442, jul. 2013.
SMITH, W.; LEWIS, M. Toward a theory of paradox: A dynamic equilibrium model of organizing. Academy of Management Review, [s.l.], v. 36, n. 2, p. 381-403, apr. 2011.

TRACEY, P.; PHILLIPS, N.; JARVIS, O. Bridging institutional entrepreneurship and the creation of new organizational forms: A multilevel model. Organization Science, [s.1.], v. 22, n. 1, p. 60-80, feb. 2011.

WILLIAMS, C.; NADIN, S. Beyond the commercial versus social entrepreneurship divide: Some lessons from English localities. Social Enterprise Journal, [s.l.], v. 7, n. 2, p. 118-129, 2011.

YIN, R.. Estudo de caso: planejamento e métodos. Porto Alegre: Bookman, 2001.

YUNUS, M. Creating a world without poverty: social business and the future of capitalism. New York: Public Affairs, 2006.

YUNUS, M.; MOINGEON, B.; LEHMANNORTEGA, L. Building social business models: lessons from the Grameen experience. Long range planning, [s.l.], v. 43, n. 2, p. 308-325, apr. 2010.

ZAHRA, S. et al. A typology of social entrepreneurs: motives, search processes and ethical challenges. Jornal of Business Venturing, [s.l.], v. 24, n. 5 , p. 509-532, 2009. 